\title{
A Decisão de Tentar o Suicídio sob a Lente Fenomenológico-existencial
}

\section{Sartriana}

\author{
Carlos Ming-Wau* \\ Universidade de Fortaleza - UNIFOR, Fortaleza, CE, Brasil \\ ORCID: https://orcid.org/0000-0002-2995-4698 \\ Georges Daniel Janja Bloc Boris** \\ Universidade de Fortaleza - UNIFOR, Fortaleza, CE, Brasil \\ ORCID: https://orcid.org/0000-0003-0726-1767 \\ Anna Karynne Melo*** \\ Universidade de Fortaleza - UNIFOR, Fortaleza, CE, Brasil \\ ORCID: https://orcid.org/0000-0003-4783-8356 \\ Raimunda Magalhães da Silva**** \\ Universidade de Fortaleza - UNIFOR, Fortaleza, CE, Brasil \\ ORCID: https://orcid.org/0000-0001-5353-7520
}

\section{RESUMO}

A tentativa de suicídio é uma escolha entre viver ou morrer decidida a partir da vivência da liberdade. Neste artigo, objetivamos compreender a experiência vivida da decisão de tentar o suicídio. Trata-se de uma pesquisa qualitativa com abordagem fenomenológica, cujo suporte teórico-metodológico foi endossado pela fenomenologia existencial de Sartre. Utilizamos entrevistas fenomenológicas para coletar os depoimentos de cinco pessoas adultas que tentaram suicídio, abordadas por meio desta questão: como foi a sua experiência de tentar o suicídio? A análise dos dados revelou os sentidos que os participantes atribuíam à sua decisão de tentar o suicídio. A partir dos depoimentos, elencamos duas unidades de sentido: Morte, vida e liberdade nas tentativas de suicídio e "Acho que a morte é melhor do que viver neste mundo". Analisamos e discutimos como os participantes vivenciaram a decisão de morrer ou viver nas situações de adversidade que surgiam nos contextos reais de suas histórias de vida. Concluímos que a tentativa de suicídio é uma forma de escapar de situações de infortúnios, conflitos, desamparo, desespero, angústia e sofrimento, quando os participantes foram convocados a escolher, como uma expressão da liberdade ontológica, entre suportar os malogros existenciais e decidir dar cabo de suas vidas.

Palavras-chave: suicídio, tentativa de suicídio, comportamento suicida, fenomenologia existencial, Sartre. 


\title{
The Decision to Attempt Suicide through the Phenomenological-existential
}

\section{Lens of Sartre}

\begin{abstract}
Suicide attempt is a choice between living or dying decided from the experience of freedom. In this article, we aim to understand the experience of the decision to attempt suicide. It is a qualitative research, with a phenomenological approach and theoretical and methodological support endorsed by Sartre's existential phenomenology. We used phenomenological interviews to collect the testimonies of five adults who attempted suicide, addressed through the following question: how was your experience of attempting suicide? Data analysis revealed the meanings that participants attributed to their decision to attempt suicide. From the collected testimonies, we list two units of meaning: death, life and freedom in suicide attempts and "I think death is better than living in this world". We analyzed and discussed how the participants experienced the decision to die or live in situations of adversity that arose in the real contexts of their life stories. We conclude that the suicide attempt is a way to escape situations of misfortune, conflicts, helplessness, despair, anguish and suffering, when participants were faced with the choice of dealing with existential failures or ending their lives, as an expression of their ontological freedom.
\end{abstract}

Keywords: suicide, suicide attempt, suicidal behavior, existential phenomenology, Sartre.

\section{La Decisión de Intentar Suicidarse bajo el Lente Fenomenológico-}

\author{
existencial de Sartre
}

\section{RESUMEN}

El intento de suicidio es una elección entre vivir o morir, determinado por la experiencia de la libertad. Nuestro objetivo es comprender la experiencia de la decisión de intentar suicidarse. Es una investigación cualitativa con un enfoque fenomenológico, cuyo apoyo teórico y metodológico fue avalado por la fenomenología existencial de Sartre. Utilizamos entrevistas fenomenológicas para recopilar los testimonios de cinco adultos que intentaron suicidarse, abordados a través de esta pregunta: ¿cómo fue tu experiencia al intentar suicidarte? El análisis de los datos reveló los significados que los participantes atribuyeron a su decisión de intentar suicidarse. A partir de los testimonios, enumeramos dos unidades de significado: Muerte, vida y libertad en los intentos de suicidio y "Creo que la muerte es mejor que vivir en este mundo". Analizamos y discutimos cómo los participantes experimentaron la decisión de morir o vivir en situaciones de adversidad que surgieron en los contextos reales de sus historias de vida. Concluimos que el intento de suicidio es una forma de escapar de situaciones de desgracia, conflictos, impotencia, desesperación, angustia y sufrimiento, cuando se pidió a los participantes que eligieran, como expresión de libertad ontológica, entre perdurar fallas existenciales y decidir terminar con sus vidas.

Palabras clave: suicidio, intento de suicidio, comportamiento suicida, fenomenología existencial, Sartre. 
Os atos que as pessoas realizam contra si mesmas são denominados de lesões autoprovocadas e englobam o comportamento suicida e as autoagressões (Bahia, Avanci, Pinto, \& Minayo, 2020). As práticas de automutilação são consideradas autoagressões, que incluem a realização de mordidas, arranhões e cortes na pele, e, nos casos mais graves, a amputação de algum membro do corpo (Dalgalarrondo, 2019). Por sua vez, o comportamento suicida diz respeito ao "processo que tem seu início desde a ideação, a tentativa, as ameaças até o ato consumado, isto é, a morte" (Fukumitsu, 2014, p. 272).

Sobre o comportamento suicida, a Organização Mundial de Saúde (World Health Organization [WHO], 2019) aponta que, a cada 3 segundos, ocorre uma tentativa de suicídio, e que, a cada 40 segundos, uma pessoa se mata em algum lugar do mundo. Estima-se que, por ano, no mundo, cerca de 800 mil pessoas morrem por suicídio, o que implica considerar que este fenômeno dizima uma quantidade significativa da população mundial. A subnotificação do comportamento suicida impossibilita acompanhar com precisão os dados quantitativos de tentativas e de mortes por suicídio, haja vista que, em alguns casos, antes do ato consumado, são realizadas várias tentativas de suicídio (Minayo, Figueiredo, \& Mangas, 2019).

As estimativas epidemiológicas sugerem que, para cada suicídio consumado, podem ter ocorrido, em média, 10 a 20 tentativas de suicídio, sem contar as que não chegam aos serviços de saúde e as que são subnotificadas. No caso dos suicídios consumados, a subnotificação ocorre quando se busca encobrir o suicídio como a causas mortis (Santa \& Cantilino, 2016). Estes episódios sugerem que, em torno do comportamento suicida, há um silêncio legitimado sociocultural que impede as pessoas de falar a seu respeito (Silva, Sousa, Vieira, Caldas, \& Minayo, 2018). Contudo, mesmo com a recorrente recusa dos agentes sociais de tratar do assunto, o comportamento suicida é uma importante pauta de discussão na agenda global, considerado um problema de saúde pública, multifatorial e complexo devido às suas altas cifras, tanto no que se refere às tentativas de suicídio quanto às mortes por suicídio (WHO, 2019).

O comportamento suicida, como fenômeno multifatorial e complexo, envolve fatores psicológicos, culturais, biológicos, genéticos e sociais, ou seja, engloba toda a história de vida do sujeito e também perpassa as suas relações com as outras pessoas, com a sociedade e com a cultura (Souza \& Moreira, 2018). Devido a esta gama de fatores constituintes, a compreensão do comportamento suicida deve enfatizar os sentidos que estão em jogo na ideação e na tentativa de pôr fim à própria vida, abstendo-se de ressaltar somente as suas causas. Destacamos que, neste artigo, optamos pela investigação fenomenológica de apenas uma das facetas do comportamento suicida, no caso, a tentativa de suicídio. 
Conforme Bahia et al. (2020), os estudos sobre as tentativas de suicídio podem colaborar na identificação dos fatores de risco que levam a pessoa ao ato, bem como à sua prevenção. Neste contexto, Silva et al. (2018) afirmam que pessoas que já tentaram o suicídio se tornam mais propensas a manter pensamentos de morte, o que aumenta o risco de novamente tentarem se matar. Por sua vez, Feijoo (2018) advoga que, na investigação fenomenológico-existencial, a ênfase deve recair na compreensão dos sentidos que estão em jogo na (in)decisão de acabar com a própria vida, sendo uma forma de prevenção do suicídio. Ainda, aponta a necessidade da realização de estudos fenomenológico-existenciais que se debrucem sobre o comportamento suicida, pouco investigado por pesquisadores nesta perspectiva. Assim, elegemos a fenomenologia existencial de Sartre para a análise e a discussão dos sentidos que estão em jogo na experiência vivida de pessoas que tentaram o suicídio.

A tentativa de suicídio é uma escolha entre viver ou morrer decidida a partir da vivência da liberdade, tema propício a uma discussão sob a lente fenomenológico-existencial de Sartre. A investigação fenomenológica sartriana é considerada apriorística, pois parte do pressuposto de que o pesquisador não sabe as respostas para o seu problema de pesquisa. Então, busca, a partir da experiência vivida dos participantes da pesquisa, "compreender o que ele[s] 'quer[em] dizer'” (Sartre, 1943/2015, p. 632) acerca de suas tentativas de suicídio. Deste modo, neste artigo, apresentamos um recorte de uma dissertação de mestrado que investigou os sentidos de tentativas de suicídio à luz da fenomenologia existencial de Sartre. Assim, objetivamos compreender a experiência vivida da decisão de tentar o suicídio.

\section{O Comportamento Suicida na Ótica Sartriana}

Em sua obra magna $O$ ser e o nada: ensaio de ontologia fenomenológica, Sartre (1943/2015) tratou do fenômeno suicídio de modos distintos. Num primeiro momento, nesta obra, o filósofo discorreu sobre a 'conduta suicida', relacionando-a à vertigem angustiante da liberdade, resultante das escolhas humanas. Mais adiante, advogou que o suicídio é uma escolha do homem como o último ato da sua vida. E, quando tratou da absurdidade da morte, explicitou que o suicídio é um absurdo cuja intenção é finalizar o projeto de ser.

Para o filósofo, na conferência de 1946, cujo enfoque era a defesa do seu existencialismo como um humanismo, "o homem é, inicialmente, um projeto que se vive enquanto sujeito" porque existe antes de qualquer coisa; assim, "nada existe de inteligível sob o céu e o homem será, antes de mais nada, o que ele tiver projetado ser" (Sartre, 1946/2014, 
p. 19-20). É por meio do projeto de ser que o homem dá sentido à sua vida. Norberto (2017) sinaliza que o projeto de ser convoca escolhas e ações humanas sem a garantia de qualquer tipo de proteção ou determinação a priori. Desta forma, as escolhas põem o homem frente à angústia, considerada por Boris e Barata (2017) “um importante catalisador do projecto de ser que o ser humano constrói ao longo de sua existência” (p. 157). Assim, Sartre (1943/2015) definiu que "a angústia é o modo de ser da liberdade como consciência de ser; é na angústia que a liberdade está em seu ser colocando-se a si mesma em questão" (p. 72).

A vivência da angústia, conforme dispõe a fenomenologia existencial sartriana, aproxima-se de uma sensação de aperto ou de estrangulamento (Boris \& Barata, 2017), ou ainda, como consta em A Náusea (Sartre, 1938/2016), nas palavras de Roquentin, é "uma espécie de enjoo adocicado" (p. 23). Para Silveira (2016), a angústia é uma característica primordialmente humana por ser a expressão da liberdade, pois, se o homem não fosse livre, não sentiria angústia. Contudo, Mattos, Ewald e Castro (2012) explicitam que "a liberdade pode paralisar os sujeitos, levando-os a dilemas éticos e a pensamentos inquietantes" (p. 730), fato que tem o potencial de causar mal-estar e conflitos frente às diversas ações possíveis a partir de suas escolhas. Sobre esta questão, influenciado por Kierkegaard (1844/1982), Sartre (1943/2015), descreveu a vertigem angustiante da liberdade como uma conduta suicida do homem diante de um precipício:

[...] Aproximo-me do precipício e meu olhar procura a mim mesmo lá no fundo. A partir daí, jogo com meus possíveis. Meus olhos, percorrendo o abismo de alto a baixo, mimetizam minha possível queda, realizando-a simbolicamente; ao mesmo tempo, a conduta suicida, pelo fato de converter-se em "meu possível" possível, faz surgir por sua vez motivos possíveis para adotá-la (o suicídio fará cessar a angústia) [...] (Sartre 1943/2015, p. 76)

Podemos considerar a conduta suicida, descrita pelo filósofo, como uma das faces do que Fukumitsu (2014) chamou de comportamento suicida, que como tratamos anteriormente, engloba a ideação, o plano de realização de algo contra si mesmo, a tentativa e a morte por suicídio. Para o filósofo existencialista, esta conduta tem a intenção de minar a angústia da existência. Contudo, como Campos (2017) ressaltou, o homem se esforça na busca de alívio para as experiências decorrentes da angústia, mas este esforço é em vão, pois não pode escapar de sua condição de liberdade. A tese advogada por Sartre (1943/2015) é que o homem é angústia e que dela não pode escapar, mesmo que crie subterfúgios para suprimi-la. Desta 
forma, a conduta suicida evidencia a possibilidade de se jogar ou não no precipício, apontando os dilemas que o homem vivencia ao se deparar com sua liberdade de escolha.

Ao lançar mão do comportamento suicida nos momentos em que as desventuras malogram a sua existência, o homem pode buscar a libertação dos infortúnios da vida. Nas situações em que o desespero (Feijoo, 2018) e os sentimentos de solidão, de tristeza e de fracasso se fazem presentes (Castro \& Ehrlich, 2016), é possível que a escolha seja realizar algo contra si mesmo, como uma tentativa de suicídio. Para Sartre (1943/2015), "a realidadehumana pode escolher-se como bem entenda, mas não pode não escolher-se; sequer pode recusar-se a ser: o suicídio, com efeito, é escolha e afirmação de ser" (p. 590). Neste contexto, o comportamento suicida é uma escolha possível de realizar, pois o filósofo acentuou que o homem é livre para escolher o que fará com o seu projeto de ser (Sartre, 1946/2014).

Portanto, o suicídio, na ótica sartriana, "é uma absurdidade que faz minha vida soçobrar no absurdo" (Sartre, 1943/2015, p. 662), pois interrompe as possibilidades de vir-aser. Sobre o suicídio como um absurdo, Castro e Ehrlich (2016) afirmam que este ato "não se trata de um projeto de ser, posto que é a aniquilação de toda e qualquer possibilidade de ser" (p. 167). Todavia, no comportamento suicida, o homem almeja interromper o seu horizonte de possibilidades, que, para Schneider (2017), é um importante elemento que constitui a existência humana e o direciona para as decisões sobre os rumos do seu projeto de ser. Então, o suicídio é uma escolha, mesmo que, nesta alternativa, o homem prefira negar a responsabilidade por realizar escolhas, pondo fim à sua existência.

\section{Método}

O delineamento deste estudo corresponde a uma pesquisa qualitativa com abordagem fenomenológica, cujo suporte teórico-metodológico foi endossado pela perspectiva fenomenológico-existencial de Sartre. O filósofo considerava que este tipo de estudo “introduz no fim uma alteração qualitativa que, em consequência, não é mensurável” (Sartre, 1947/2004, p. 211). Esta pesquisa tem o interesse de compreender a experiência vivida da decisão de tentar o suicídio, o que a aproxima da filosofia da existência de Sartre e da psicologia existencial por conta do foco nas vivências concretas das pessoas. Feijoo e Mattar (2014) afirmam que "a primeira realiza sua tarefa pela reflexão filosófica, a segunda centra-se na materialidade da existência em sua realidade concreta" (p. 442). Para Benevides e Boris (2020), a investigação fenomenológica a partir da lente sartriana considera que o ser humano 
é um sujeito livre, concreto e situado no mundo, sendo imprescindível compreendê-lo no contexto em que se insere a sua existência.

Os participantes da pesquisa foram cinco pessoas adultas que tentaram o suicídio, ao exercerem suas liberdades de escolhas. O campo do estudo foi o Programa de Apoio à Vida PRAVIDA, do Hospital Universitário Walter Cantídio - HUWC, vinculado à Faculdade de Medicina da Universidade Federal do Ceará - UFC. O PRAVIDA é um serviço ambulatorial especializado em prevenção do suicídio que atende a população de Fortaleza, a sua região metropolitana e cidades do interior do estado do Ceará. Para que este estudo fosse realizado no PRAVIDA, obtivemos a aprovação dos Comitês de Ética em Pesquisa em Seres Humanos da Universidade de Fortaleza - UNIFOR (Parecer: 3.192.960/ CAAE: 07454819.2.0000.5052) e do HUWC/UFC (Parecer: 3.311.435/ CAAE: 07454819.2.3001.5045).

De acordo com Feijoo (2018), na pesquisa fenomenológica, o importante é a compreensão do fenômeno da forma como ele se apresenta e como os sujeitos colaboradores lhe atribui sentidos. Assim, o foco desta investigação foi a compreensão dos sentidos que os participantes da pesquisa conferem às suas decisões de tentar o suicídio. Dito de outro modo, buscamos compreender como eles significaram as escolhas que realizaram com a intenção de pôr fim às suas vidas. Foi realizada uma entrevista fenomenológica com cada participante, que permitiu a descrição das suas experiências vividas, cuja abordagem foi feita de forma indireta por meio desta questão norteadora: como foi a sua experiência de tentar o suicídio?

As entrevistas foram realizadas, entre os meses de maio e junho de 2019 , com os pacientes em atendimento no PRAVIDA que haviam tentado suicídio. Após o convite e sua aceitação por parte dos participantes de colaborar com a investigação, as entrevistas foram iniciadas com a leitura e a assinatura, em duas vias, do Termo de Consentimento Livre e Esclarecido - TCLE, pactuando o sigilo e o anonimato das informações coletadas. Nomeamos os participantes da pesquisa com os seguintes pseudônimos: Eduardo, de 48 anos; Estela, de 35 anos; Talita, de 45 anos; Fabrícia, de 23 anos; e Davi, de 29 anos. As entrevistas ocorreram nas salas do Ambulatório de Saúde Mental do HUWC, espaços em que são realizados os atendimentos do PRAVIDA, locais que permitiram que os participantes descrevessem suas experiências livremente e sob sigilo profissional.

Durante as entrevistas, como recurso metodológico, foi utilizada a redução fenomenológica, suspendendo os conhecimentos prévios sobre o fenômeno suicídio e possíveis atitudes moralizantes a seu respeito e que pudessem incidir numa classificação das tentativas de suicídio como atitudes boas ou más, criminosas ou pecaminosas, bem como atos 
psicopatológicos. Para Sartre (1936/2008), a redução fenomenológica é essencial neste tipo de pesquisa, pois permite a apreensão dos sentidos atribuídos ao fenômeno vivido pelos colaboradores da investigação, conforme eles se mostram aos pesquisadores, que abrem mão da atitude natural, ou seja, de perceber o fenômeno a partir de seus conceitos preestabelecidos, do senso comum ou de julgamentos morais.

A redução fenomenológica também foi essencial nos procedimentos para a análise dos dados coletados. Foi realizada a transcrição integral dos áudios das entrevistas e a leitura minuciosa do seu conteúdo a fim de compreender as vivências descritas pelos participantes da pesquisa sobre a decisão de tentar o suicídio. Para Sartre (1939/2013), durante a análise dos dados de uma pesquisa, a redução fenomenológica possibilita a compreensão do fenômeno investigado e das suas relações com o mundo em que a existência humana se insere, ou seja, a situação em que o fenômeno se manifesta, por meio da sua descrição fenomenológica. Neste momento, dividimos as falas dos participantes em temas emergentes, com o intuito de apreender "o que se mostra, sem transformá-lo e sem prescindir da visada, apenas acompanhando os vetores daquilo que se apresenta, acompanhando a mobilidade estrutural do fenômeno" (Feijoo \& Mattar, 2014, p. 444-445).

A partir dos temas emergentes manifestados na descrição da situação vivida e expressa nas falas dos participantes da pesquisa, passamos ao registro das suas experiências de tentativas de suicídio em seus diversos sentidos. Partimos do próprio fenômeno, que, para o filósofo, "é o que se manifesta, e o ser se manifesta a todos de algum modo, pois dele podemos falar e dele temos certa compreensão" (Sartre, 1943/2015, p. 19). Desta forma, organizamos as falas dos participantes em unidades de sentido e acompanhamos as manifestações singulares e universais sobre a decisão de tentar o suicídio com o intuito de analisá-las e discuti-las sob a lente fenomenológico-existencial sartriana.

\section{Resultados e Discussão}

Os participantes da pesquisa descreveram como decidiram suas tentativas de suicídio, enfatizando que estes atos ocorreram em momentos de adversidade, de cobranças sociais e de conflitos, tanto consigo mesmos quanto com outras pessoas. Também trouxeram à tona os contextos em que se deram suas vontades de morte e as circunstâncias que potencializaram as suas tentativas de suicídio. A compreensão de seus depoimentos, sob a lente sartriana, partiu do pressuposto de que a decisão de provocar a própria morte ocorreu em situação (Sartre, 1943/2015), ou seja, nos contextos reais em que suas existências se desenvolviam. Conforme 
Sartre (1939/2013), compreender as escolhas humanas corresponde a um interesse pelo homem em situação. O filósofo sugeriu que a psicologia voltasse seu olhar para "o homem no mundo, tal como ele se apresenta através de inúmeras situações: no café, em família, na guerra" (p. 27).

Deste modo, compreendendo os contextos em que se inserem e se desenvolvem as existências dos participantes da pesquisa, buscamos desvelar os sentidos por eles atribuídos às suas tentativas de suicídio. A partir dos depoimentos colhidos nas entrevistas fenomenológicas realizadas, revelaram-se duas unidades de sentido: Morte, vida e liberdade nas tentativas de suicídio e "Acho que a morte é melhor do que viver neste mundo". Esta última unidade de sentido foi nomeada a partir do fragmento do depoimento de um dos participantes.

\section{Morte, vida e liberdade nas tentativas de suicídio}

Nesta unidade de sentido, analisamos e discutimos os depoimentos dos participantes da pesquisa que expressaram sua vivência da liberdade ao escolherem entre a vida e a morte. Eduardo revelou que sua decisão de tentar o suicídio ocorreu após o acidente vascular cerebral (AVC) de seu pai, episódio que poderia tê-lo levado à morte. Para Talita, seu ato de cortar os pulsos ocorreu num momento de desespero após experienciar alucinações auditivas. Estela e Fabrícia afirmaram que suas tentativas de suicídio por meio da ingestão de medicamentos tinham a intenção de que entrassem num sono profundo para descansar das adversidades que vinham enfrentando. Davi se declarou gay e acreditava que a morte por suicídio seria a libertação dos seus malogros existenciais.

Talita associou sua tentativa de suicídio a um possível diagnóstico psicopatológico, considerando que "estava doente". Contou que havia sofrido com alucinações auditivas, que, de acordo com Dalgalarrondo (2019), é um dos principais sintomas do transtorno do espectro da esquizofrenia. Talita fez cortes profundos em seus pulsos, tendo sido submetida a procedimentos cirúrgicos e a internação em hospital geral. Questionada sobre o conteúdo das vozes que ouvia, disse que elas não lhe sugeriam o suicídio, mas que lhe faziam xingamentos. Durante a entrevista, acrescentou:

A minha tentativa de suicídio foi em um momento de desespero. Eu nunca tinha ficado tão desesperada. Na hora que eu cortei os meus pulsos, eu estava desesperada (...). Era vontade de morrer que eu 'tava' sentindo. 
O desespero, como a angústia, é um sentimento constituinte da liberdade de escolha, ou seja, para Sartre (1946/2016), “quer dizer que nós só poderemos contar com aquilo que depende de nossa vontade ou com o conjunto das probabilidades que tornam a nossa ação provável" (pp. 28-29). Talita afirmou que sua vontade era de morrer, pois não sabia lidar com as alucinações auditivas, vivências que lhe acometiam intenso sofrimento. Para Boris e Barata (2017), o desespero pode deixar as pessoas impotentes e incapacitar as ações humanas, como ocorreu com Talita. Desesperada, escolheu o suicídio, pois, naquele momento, sentia-se impotente por não avaliar a veracidade das vozes. Neste sentido, desferir cortes em seus pulsos foi a forma que encontrou para suportar as alucinações auditivas, que, para Talita, eram resquícios do seu diagnóstico psicopatológico, pois se considerava doente. O tema da psicopatologia também apareceu na fala de Eduardo:

Parei de trabalhar para cuidar do meu pai, que teve um AVC. Eu já vinha com uns pensamentos bestas. Acho que é depressão. Quando eu chegava em casa, passava a noite sem dormir, só pensando. Não foi por causa do AVC. Antes disso acontecer, eu já vinha pensando (...).

Eduardo enfatizou que já vinha com alguns pensamentos de morte e também percebia uma diminuição do sono e do apetite, episódios que, para ele, seriam sintomas de um transtorno depressivo. Souza e Moreira (2018), num estudo fenomenológico, destacam a relação entre depressão e suicídio e advertem que não há como restringi-lo apenas ao diagnóstico psicopatológico, mas advogam a importância de compreender o suicídio sob o prisma das relações com o outro. O AVC do pai de Eduardo foi uma situação vivida em que ele se percebeu desnorteado, o que o impulsionou a alterar seu projeto de ser. Escolheu abandonar o trabalho para cuidar de seu genitor, acrescentando: "depois disso, eu me senti angustiado". Eduardo modificou o seu projeto de ser, baseado no seu "conjunto de relações abstratas sustentadas pela livre escolha" (Sartre, 1943/2015, p. 637): no caso, a vivência do AVC e os cuidados realizados junto a seu pai.

$\mathrm{O}$ ato de escolher evoca a vivência da angústia, catalisador fundamental do desenvolvimento do projeto de ser (Boris \& Barata, 2017); contudo, é em vão que o homem cria subterfúgios a fim de suprimi-la da sua existência (Campos, 2017). Eduardo escolheu o suicídio quando se angustiou por ter deixado o trabalho para cuidar de seu pai. O filósofo caracterizou esta angústia como voltada ao passado, quando o homem percebe que as escolhas 
de outrora fracassaram (Sartre, 1943/2015). Compreendemos que, por meio de sua escolha do suicídio, Eduardo buscava amenizar a angústia que havia se acentuado após o abandono do trabalho.

Para Mattos, Ewald e Castro (2012), a liberdade tem o potencial de causar mal-estar frente às possibilidades de escolha, principalmente porque as decisões ocorrem nos contextos reais da existência. A tentativa de suicídio de Eduardo não se limita a um diagnóstico psicopatológico de depressão, mas se mostrou relacionada à possibilidade de escolher cuidar ou não de seu pai. Escolher, então, convoca o sujeito a decidir qual rumo tomar (Sartre, 1946/2014), o que não o exime de se deparar com situações de conflito consigo mesmo e com as outras pessoas, como percebemos nos depoimentos seguintes.

Em suas tentativas de suicídio, Estela e Fabrícia tinham o objetivo de dormir após a ingestão de vários medicamentos:

É nunca mais acordar. Você vai dormir com os problemas e dores, e só a ideia de ir deitar, sabendo que não vai acordar e não vai mais sentir aquilo que você estava sentindo (...). A gente não pensa na palavra 'morrer': morrer é tão forte, morrer é feio. Só quer dormir. Só quer ter paz e nunca mais acordar (Estela).

Quando eu tentei o suicídio, eu namorava um menino, e minha mãe não gostava dele. Os dois sempre 'batiam de frente', e eu ficava entre eles, apavorada e agoniada. A minha mãe não queria que eu namorasse com ele, queria que eu terminasse o namoro. Ele queria que fôssemos morar juntos. Um dia, eu fiquei desesperada. Comecei a me cortar. Meu namorado soube e me levou para o hospital mental e fui internada (Fabrícia).

Em um momento da entrevista, Fabrícia contou que, após a ingestão dos medicamentos, entrava em um sono profundo, e, algumas vezes, acordava no dia seguinte. Por sua vez, Estela apontou que sua intenção era dormir e não acordar para enfrentar os seus problemas. Na ótica sartriana, "o sono é às vezes uma fuga diante da decisão a tomar" (Sartre, 1939/2013, p. 49), ou seja, ambas perseguiam um sono que as aliviasse de seus conflitos existenciais. Fabrícia precisava decidir se ficaria com a mãe ou com o namorado e Estela desejava ter paz, não confrontar as outras pessoas. Para Cortés (2017), “o ato de escolher é o que constitui o ser livre, na possibilidade constante de decidir o que vai fazer e como vai lidar com o que vivenciou ou vivencia” (p. 308). Estela e Fabrícia lidaram com as situações de 
conflito com o outro por meio de um sono que lhes permitisse postergar suas decisões sobre a direção dos seus projetos de ser.

Para Sartre (1946/2014), o homem sempre se defronta com situações que requerem escolhas, o que significa considerar que, a todo instante, é preciso escolher, dada a sua condição de liberdade ontológica. Estela e Fabrícia, com o intuito de dormir para não entrarem em contato com as decisões em que suas relações com o outro estavam em jogo, escolheram o suicídio. Fabrícia lançou mão da automutilação, num momento de desespero, a fim de aliviar o conflito entre escolher sua mãe ou o seu namorado, ou seja, vivenciando uma desarmonia entre o que queria e o que poderia escolher (Feijoo, 2018). Ora, na vivência da liberdade frente às diversas possibilidades de escolha, os atos contra si mesmo, como a automutilação, ou o que foi nomeado pelo filósofo (Sartre, 1943/2015) de conduta suicida tem a capacidade de cessar a angústia, mesmo que apenas por um momento.

Por sua vez, Davi assinalou que sua tentativa de suicídio foi um ato de libertação:

Eu acho que, morrendo, eu iria me libertar, porque me sinto preso: me libertar das minhas loucuras e do que as pessoas esperam de mim. Morrer é como se fosse uma liberdade.

Davi acrescentou que "morrer seria uma saída" capaz de libertá-lo dos seus malogros existenciais. Dutra (2011) e Feijoo (2018) constataram, em suas investigações fenomenológicas, que o suicídio foi visualizado como a única saída por aqueles que pensaram ou que tentaram pôr fim às suas vidas. Compreendemos, no caso de Davi, que a tentativa de suicídio foi considerada a única possibilidade de exercer sua liberdade. Para Schneider (2017), "a liberdade, quer dizer, o fato de estarmos, constantemente, escolhendo nosso ser nunca é gratuita: ela se dá em uma estrutura de escolha, que nos coloca certos possíveis" (p. 138). Neste contexto, Davi almejava se libertar de uma prisão imposta pelas pessoas de seu convívio que lhe pressionavam a ter um modo de vida que não convinha com sua vontade.

De acordo com Sartre (1943/2015), o suicídio é uma atitude extrema que ocorre na indiferença com o outro, a fim de suportá-la. Contudo, o filósofo acrescentou que "estamos já lançados no mundo diante do Outro; nosso surgimento é livre limitação de sua liberdade, e nada, sequer o suicídio, pode modificar esta situação originária" (p. 508). Compreendemos que Davi escolheu a tentativa de suicídio, pondo em jogo a negação de ser e de estar no mundo conforme a vontade do outro. No seu depoimento, parecia não perceber outras possibilidades que pudesse lançar mão para exercer sua liberdade ontológica. Por meio da 
tentativa de suicídio, Davi buscava se libertar das amarras que continham sua liberdade, embora, nesta escolha, o desfecho pudesse ter sido a morte, o que implicaria na recusa de ser e de estar no mundo.

\section{"Acho que a morte é melhor do que viver neste mundo"}

A análise e discussão das falas dos participantes da pesquisa, nesta unidade de sentido, encaminhou-se para os modos como lidavam com as situações de adversidade nos contextos das tentativas de suicídio. Fabrícia apontou sua recusa de viver num mundo em que as pessoas são más e buscam apenas o sucesso e a riqueza. Davi não desejava viver num mundo que o aprisiona em categorias com características específicas de comportamento. Conforme Eduardo, a experiência de tratar do pai com AVC lhe fez relembrar as perdas de sua mãe e de seus irmãos. Por sua vez, Talita, num primeiro momento, pensava que a morte eliminaria as alucinações auditivas. Para Estela, a morte seria a saída para evitar o contato com as pessoas, principalmente com aquelas que queriam vê-la sempre sorrindo:

As pessoas só querem ver o que elas querem. Elas não querem ver a realidade. Elas acham que as pessoas têm que estar sempre alegres e sorrindo. Acham que ninguém tem problemas. Mas todo mundo tem e, às vezes, não somos compreendidos (...). Eu só quero dormir mesmo (...). Eu não vou ter mais que enfrentar as pessoas.

Com sua tentativa de suicídio, Estela buscava entorpecer sua existência para não entrar em contato com aqueles que queriam saber como estava sua vida. Ao ser socorrida por quem a levava a uma emergência médica, sentia raiva, pois era interrompida pela ajuda do outro no momento em que se considerava frágil. Para Sartre (1943/2015), compartilhamos o mundo com o outro, que também nos olha. Concomitantemente, percebemos que somos vistos por seu olhar, que tem a capacidade de dizer o que estamos sentindo.

Estela não desejava ser vista pelos outros como uma mulher com problemas, enfatizando que as pessoas só veem o que querem. Conforme argumenta Campos (2017), numa perspectiva sartriana, "quando o outro nos olha tomamos consciência de que somos vistos, de que temos um corpo, de que somos vulneráveis, de que ocupamos um lugar no mundo" (p. 102). Frente ao olhar dos outros, Estela se dava conta de suas fragilidades, evitadas por meio do entorpecimento de seus dilemas existenciais, usando o sono para poupála do seu contato e de não ser compreendida por eles. 
Schneider (2017) acentua que as relações com os outros são fundamentais para a constituição humana, pois a existência é construída a partir de relações de reciprocidade e de cooperação entre as pessoas. Assim, por meio de ações de autodestruição, Estela expressava um pedido de ajuda aos outros, em seus momentos de vulnerabilidade, mesmo que de forma ambígua, recorrendo a uma fuga mediante a ingestão excessiva de medicamentos e o consequente sono fatal.

Diferentemente de Estela, Fabrícia deu ênfase à sua recusa de viver num mundo no qual não coadunava com os ideais das outras pessoas, conforme destacou:

Às vezes, eu penso que não quero o que as pessoas querem: por exemplo, trabalhar, estudar e ter que ser alguma coisa. Se você não tiver dinheiro, você vai ser menosprezada pelas pessoas, igual os mendigos que as pessoas fingem não ver. Eu fico pensando e não quero viver num mundo em que as pessoas só pensam em dinheiro.

Para Sartre (1947/2004), “o mundo, deixando de ser instrumento do êxito, torna-se instrumento do fracasso. Ei-lo percorrido por uma obscura finalidade; o mundo passa a servir por seu coeficiente de adversidade: tanto mais humano quanto mais hostil ao homem" (p. 31). Fabrícia desenvolveu ressentimento ao modo como as pessoas vivem no mundo, considerando que as pessoas são más e desejam somente bens materiais, sem se importar com o próximo. Não querer o que a maioria das pessoas almeja foi a expressão de sua singularidade e de sua liberdade de escolha. O mundo em que atualmente vive, para ela, é inóspito. Fabrícia idealiza um mundo diferente para si mesma e para a humanidade, mas, como não conseguia concretizá-lo, decidiu deixá-lo.

Do ponto de vista de Sartre (1943/2015), as pessoas não escolhem o mundo em que nascem, mas podem mudá-lo, ou seja, "ser livre não é escolher o mundo histórico onde surgimos - o que não teria sentido -, mas escolher a si mesmo no mundo, não importa qual seja" (p. 640). Fabrícia não pôde escolher o mundo em que nasceu, mas pode se fazer nele e modificar a si mesma e ao mundo. No entanto, escolheu entorpecer seus sentimentos, recusando-se a viver num mundo diferente do que projetava. De acordo com a perspectiva sartriana, as pessoas, ao escolherem para si mesmas, escolhem também para toda a humanidade (Sartre, 1946/2014). Ao escolher a tentativa de suicídio, Fabrícia demonstra à humanidade não ser possível viver num mundo marcado por desigualdades e injustiças. 
Por sua vez, Davi também se recusava viver num mundo diferente de seus ideais, pois não concordava com algumas categorizações disseminadas pelos gays:

Eu ia parar de existir. Na minha cabeça, eu ia parar de sofrer. Eu não iria mais precisar sair e ter essa sensação tão destrutiva (...), achar que eu não me encaixo. Eu sou gay. Nunca tive nenhum problema quanto a isso e minha família sempre aceitou. Mas eu me sinto diferente do que o mundo gay pede para eu ser (...). Continuo pensando que a morte é uma liberdade, que só assim que você consegue se libertar de verdade (...) de todas essas pressões, como eu falei: das minhas, das outras pessoas, do mundo que a gente vive, de não se enquadrar em nenhum dos grupos de gays.

Os grupos gays foram classificados por Davi em três tipos - "afeminados, ursos (homens fortes com corpo peludo e barba) ou intelectuais" -, mas disse que não se encaixava em nenhum deles, acentuando que se sentia inferior frente aos demais homossexuais. Sartre (1943/2015) discorreu sobre as classificações que o olhar do outro faz acerca dos comportamentos humanos. Para o filósofo, estas classificações "só podem aparecer como uma significação que minha liberdade lhes confere; quer dizer, mais uma vez, que tais significações são para o Outro, mas que só podem ser para mim caso eu as escolha” (p. 648). Ora, Davi explicitou que não tinha interesse de se adequar aos modos como os gays se organizam, agiam e se relacionam, ou seja, não escolheu tais classificações, pois elas não faziam parte do seu modo de vida; pelo contrário, buscava ser diferente do que o mundo exigia. Davi escolheu não se encaixar às classificações, o que, num certo sentido, as confirma: "se eu não sou como eles, não devo existir".

Davi também sinalizou que não pretendia fazer o que a maioria das pessoas fazia, como trabalhar e estudar, considerando a tentativa de suicídio uma libertação das pressões que sofria por não coadunar sua vida com os anseios das pessoas. De acordo Campos (2017), a liberdade não corresponde à vontade, pois ser livre é se fazer a todo instante, numa espécie de indeterminação e de incompletude. Quando Davi se recusou a aceitar o que as pessoas queriam para sua vida e a se encaixar nas tipificações dos gays, a autodestruição foi sua escolha frente à rejeição do mundo. Neste sentido, Davi buscava, conforme a ótica sartriana, superar tal "situação pelo que ele chega a fazer daquilo que se fez dele" (Sartre, 1960/1987, p. 152). 
Enquanto Estela, Fabrícia e Davi explicitaram sua recusa a viver num mundo diferente de seus ideais, Eduardo, em um momento da entrevista, associou sua desistência de viver às mortes de vários familiares próximos no passado:

Acho que foram as perdas que eu tive no passado. Eu perdi minha mãe, minha irmã e meu irmão. Minha mãe foi por causas naturais. Мeu irmão e minha irmã foram assassinados.

O episódio do AVC do seu pai evocou a memória da morte de sua mãe e de seus irmãos, já que Eduardo quase perdeu seu pai, e sua vida foi modificada ao abrir mão do seu trabalho para prover-lhe os cuidados. Aventou a possível relação de sua tentativa de suicídio às vivências de perda de familiares no passado, cujas mortes podem ter afetado sua existência de tal modo, que, num momento de intensa angústia, havia escolhido acabar com sua vida. Conforme Sartre (1943/2015), a morte do outro, "constitui-me como objeto irremediável, exatamente como minha própria morte" (p. 511). Compreendemos que Eduardo se sentiu desamparado ao cogitar a possível morte do seu pai, como havia se sentido após a perda de seus familiares. Assim, a morte de pessoas próximas fizera-o cogitar a sua própria morte.

Finalizamos a análise desta unidade de sentido com um fragmento do depoimento de Talita, que desejava pôr fim ao mundo criado pelas suas alucinações auditivas. Depois de refletir sobre o que havia acontecido consigo mesma, após sua tentativa de suicídio, Talita percebeu que este mundo, expresso pelas vozes, não era real e que poderia superá-lo:

Eu não dormia e não comia. Eu não tinha paz um instante quando aconteceu isso (...). Era muito ruim porque eu escutava muitas vozes (...). Quando eu fui refletir, eu poderia ter morrido por nada. Eu achava que tudo aquilo era real. Hoje, eu sei que não. Eu estava doente.

Para Sartre (1940/1996), a alucinação auditiva "é acompanhada por um desmoronamento provisório da percepção. Mas, quando o choque alucinatório passa, o mundo reaparece" (p. 199). Nesta fala, Talita afirma que superou suas alucinações adutivas, questionando a sua veracidade, ou seja, o mundo real reapareceu para ela. O que o punha em xeque era seu desespero de não saber lidar com suas alucinações, destacando, de forma enfática, que, por pouco, teria posto fim à sua vida. Ressaltamos que, assim como Talita, algumas pessoas se dão conta do que as confronta em suas tentativas de suicídio, resolvem 
suas questões existenciais e seguem adiante em suas vidas. Entretanto, uma parte significativa da população mundial não consegue visualizar saídas para as suas adversidades, para o seu desespero e para o consequente sofrimento, sendo o suicídio o desfecho de suas existências e, portanto, de seus projetos de ser.

\section{Considerações Finais}

A investigação sobre a experiência vivida da decisão de tentar o suicídio dos participantes deste estudo fenomenológico deu margem à compreensão dos contextos em que suas existências e seus projetos de ser vinham sendo construídos, muitas vezes conduzindo-os à percepção de sua angústia, de seu desamparo e de seu desespero, desencadeando atos de autodestruição. Deste modo, compreender suas tentativas de suicídio sob a lente da fenomenologia existencial de Sartre possibilitou a análise e a discussão do conjunto de circunstâncias concretas em que a decisão foi realizada, afastando-se de uma perspectiva causalista. Sartre concebia que o homem é um sujeito concreto que vive no mundo, cujas escolhas ocorrem em situação, aberto a um campo de possibilidades que lhe permite o exercício da liberdade, construindo-se por meio de sua própria ação no mundo, vivida a cada instante.

Diante de um fenômeno multifatorial e complexo, concluímos que a tentativa de suicídio é uma forma de escapar de situações de infortúnios, de conflitos, de desamparo, de desespero, de angústia e de sofrimento, quando os participantes da pesquisa foram convocados a escolher, como uma expressão da liberdade ontológica, entre suportar os malogros existenciais e decidir dar cabo de suas vidas. Destacamos a concepção de liberdade de Sartre, que advoga que as pessoas, ao escolherem para si mesmas, escolhem para toda a humanidade, ou seja, os participantes da pesquisa expressavam para todos os seres humanos que, quando as adversidades, a angústia, o sofrimento e o desespero se fazem presentes, a tentativa de suicídio pode ser uma escolha capaz de aplacar os malogros existenciais; entretanto, tal atitude tem o potencial de abreviar suas vidas.

Finalmente, sugerimos que sejam empreendidos estudos fenomenológico-existenciais fundamentados na lente sartriana que se debrucem sobre o lugar do outro no comportamento suicida, pois, afinal, como defendia o filósofo existencialista francês, o homem é um ser-parao-outro. Portanto, ressaltamos que as investigações sobre o comportamento suicida podem colaborar na compreensão dos sentidos desta decisão, bem como fomentam a prevenção dos atos que ensejam pôr fim à vida. 


\section{Referências}

Bahia, C. A., Avanci, J. Q., Pinto, L. W., \& Minayo, M. C. S. (2020). Notificações e internações por lesão autoprovocada em adolescentes no Brasil, 2007-2016. Epidemiologia e Serviços de Saúde, 29(2), 1-12. doi:10.5123/S167949742020000200006

Benevides, R. F. C., \& Boris, G. D. J. B. (2020). A experiência vivida de mulheres na conjugalidade contemporânea: Uma perspectiva fenomenológico-existencial. Phenomenological Studies - Revista da Abordagem Gestáltica, 26(1), 13-25. doi:10.18065/RAG.2020.v26n1.2

Boris, G. D. J. B., \& Barata, A. (2017). Angústia e Ansiedade: Um esboço históricoconceitual e uma perspectiva sartreana. In F. C. L. Castro \& M. S. Norberto (Orgs.), Sartre Hoje (Vol. 2, pp. 151-170). Porto Alegre: Fi.

Campos, C. M. (2017). Um olhar sartriano a respeito da extimidade virtual. In F. C. L. Castro \& M. S. Norberto (Orgs.), Sartre Hoje (Vol.2, pp. 101-116). Porto Alegre: Fi.

Castro, F. G., \& Ehrlich, I. F. (2016). Projeto de Ser e Situação. In F. G. Castro \& I. F. Ehrlich (Orgs.), Introdução à Psicanálise Existencial: Existencialismo, Fenomenologia e Projeto de Ser (pp. 113-176). Curitiba: Juruá.

Cortés, O. N. P. (2017). O Idiota da Família e a possibilidade de conhecer o outro: Estudo preliminar. In F. C. L. Castro \& M. S. Norberto (Orgs.), Sartre Hoje (Vol. 2, pp. 301313). Porto Alegre: Fi.

Dalgalarrondo, P. (2019). Psicopatologia e semiologia dos transtornos mentais. Porto Alegre, Artmed.

Dutra, E. (2011). Pensando o suicídio sob a ótica fenomenológica hermenêutica: Algumas considerações. Revista da Abordagem Gestáltica, 17(2), 152-157. Recuperado de http://pepsic.bvsalud.org/pdf/rag/v17n2/v17n2a06.pdf

Feijoo, A. M. L. C. (2018). Por um núcleo de atendimento clínico a pessoas em risco de suicídio. Revista da Abordagem Gestáltica, 24(2), 173-181. doi:10.18065/RAG.2018v24n2.6

Feijoo, A. M. L. C., \& Mattar, C. M. (2014). A Fenomenologia como Método de Investigação nas Filosofias da Existência e na Psicologia. Psicologia: Teoria e Pesquisa, 30(4), 441-447. Recuperado de http://scielo.br/pdf/ptp/v30n4/v30n4a09.pdf

Fukumitsu, K. O. (2014). O psicoterapeuta diante do comportamento suicida. Psicologia USP, 25(3), 270-275. doi:10.1590/0103-6564D20140001 
Kierkegaard, S. (1982). El Concepto de la Angustia (2a ed.). Madrid: Espasa-Calpe. (Obra original publicada em 1844)

Mattos, A. R., Ewald, A. P., \& Castro, F. G. (2012). Liberdade, alienação e criação literária: Reflexões sobre o homem contemporâneo a partir do existencialismo sartriano. Estudos e Pesquisas em Psicologia, 12(3), 724-766. Recuperado de http://pepsic.bvsalud.org/pdf/epp/v12n3/v12n3a03.pdf

Minayo, M. C. S., Figueiredo, A. E. B., \& Mangas, R. M. N. (2019). Estudo das publicações científicas (2002-2017) sobre ideação suicida, tentativas de suicídio e autonegligência de idosos internados em Instituições de Longa Permanência. Ciência \& Saúde Coletiva, 24(4), 1393-1404. doi:10.1590/1413-81232018244.01422019

Norberto, M. S. (2017). Sartre e o ocaso da deliberação. In F. C. L. Castro \& M. S. Norberto (Orgs.), Sartre Hoje (Vol. 1, pp. 139-156). Porto Alegre: Fi.

Santa, N. D., \& Cantilino, A. (2016). Suicídio entre médicos e Estudantes de Medicina: Revisão de Literatura. Revista Brasileira de Educação Médica, 40(4), 772-780. doi:10.1590/1981-52712015v40n4e00262015

Sartre, J.-P. (1987). Questão de método (B. Prado Jr., Trad.). São Paulo: Difel. (Obra original publicada em 1960)

Sartre, J.-P. (1996). O imaginário: Psicologia fenomenológica da imaginação (D. Machado, Trad.). São Paulo: Ática. (Obra original publicada em 1940)

Sartre, J.-P. (2004). Que é a literatura? (C. F. Moisés, Trad.). São Paulo: Ática. (Obra original publicada em 1947)

Sartre, J.-P. (2008). A imaginação (P. Neves, Trad.). Porto Alegre: L\&PM. (Obra original publicada em 1936)

Sartre, J.-P. (2013). Esboço para uma teoria das emoções (P. Neves, Trad.). Porto Alegre: L\&P. (Obra original publicada em 1939)

Sartre, J.-P. (2014). O existencialismo é um humanismo (J. B. Kreuch, Trad.). Petrópolis: Vozes. (Obra original publicada em 1946)

Sartre, J.-P. (2015). O ser e o nada: Ensaio de ontologia fenomenológica (P. Perdigão, Trad.). Petrópolis: Vozes. (Obra original publicada em 1943)

Sartre, J.-P. (2016). A náusea (R. Braga, Trad.). Rio de Janeiro: Nova Fronteira. (Obra original publicada em 1938)

Schneider, D. R. (2017). A pós-modernidade e a produção da subjetividade: Reflexões sartrianas. In F. C. L. Castro \& M. S. Norberto (Orgs.), Sartre Hoje (Vol. 2, pp. 117150). Porto Alegre: Fi. 
Silva, R. M., Sousa, G. S., Vieira, L. J. E. S., Caldas, J. M. P., \& Minayo, M. C. S. (2018). Ideação e tentativa de suicídio de mulheres idosas no nordeste do Brasil. Revista Brasileira de Enfermagem, 71(2), 807-815. doi:10.1590/0034-7167-2017-0413

Silveira, V. P. (2016). Má-fé e inconsciente: Sobre a crítica de Sartre a Freud em O ser e o nada. Doispontos:, 13(3), 39-55. doi: 10.5380/dp.v13i3.46396

Souza, C., \& Moreira, V. (2018). Tristeza, depressão e suicídio melancólico: A relação com o outro. Arquivos Brasileiros de Psicologia, 70(2), 173-185. Recuperado de http://pepsic.bvsalud.org/pdf/arbp/v70n2/13.pdf

World Health Organization [WHO] (2019). Mental health. Suicide data. Recuperado de http://www.who.int/mental_health/prevention/suicide/suicideprevent/en/

\section{Endereço para correspondência}

\section{Carlos Ming-Wau}

Rua Edmundo Bandeira, 745, Palestina, Canindé - CE, Brasil. CEP 62700-000

Endereço eletrônico: carlosmingwau@yahoo.com.br

\section{Georges Daniel Janja Bloc Boris}

Rua Luiza Miranda Coelho, 35, Engenheiro Luciano Cavalcante, Fortaleza - CE, Brasil. CEP 60811-110

Endereço eletrônico: geoboris@uol.com.br

\section{Anna Karynne Melo}

Rua Luiza Miranda Coelho, 75, Engenheiro Luciano Cavalcante, Fortaleza - CE, Brasil. CEP 60811-110

Endereço eletrônico: karynnemelo@unifor.br

\section{Raimunda Magalhães da Silva}

Rua Bento Albuquerque, 2300 apto 1102, Torre Jasmim, Cocó, Fortaleza - CE, Brasil. CEP 60.192-050

Endereço eletrônico: rmsilva@unifor.br

Recebido em: 01/07/2020

Aceito em: 04/09/2020

\section{Notas}

* Psicólogo. Graduado pelo Centro Universitário UniFanor. Mestre em Psicologia pela UNIFOR com bolsa da Fundação Cearense de Apoio ao Desenvolvimento Científico e Tecnológico.

** Pós-Doutor em Filosofia Prática. Doutor em Sociologia. Mestre em Educação. Psicólogo. Professor Titular do Programa de Pós-Graduação em Psicologia - UNIFOR.

*** Pós-doutora e Doutora em Saúde Coletiva. Psicóloga. Coordenadora da graduação em Psicologia. Professora colaboradora do Programa de Pós-Graduação em Saúde Coletiva - UNIFOR.

**** Professora titular dos Programas de Pós-Graduação em Enfermagem e de Saúde Coletiva - UNIFOR. Pesquisadora do CNPq. 
Financiamento: A pesquisa relatada no manuscrito foi financiada com a bolsa de mestrado do primeiro autor, pela Fundação Cearense de Apoio ao Desenvolvimento Científico e Tecnológico - FUNCAP. A quarta autora tem bolsa de produtividade do CNPq 1D.

Agradecimentos: Aos coordenadores do Programa de Apoio à Vida - PRAVIDA, da Universidade Federal do Ceará - UFC, pelo apoio e incentivo durante a pesquisa.

Este artigo de revista Estudos e Pesquisas em Psicologia é licenciado sob uma Licença Creative Commons Atribuição-Não Comercial 3.0 Não Adaptada. 